\title{
Padrão eletroforético de proteínas resistentes ao calor em sementes de milho
}

\author{
Solange Carvalho Barrios Roveri José(1), Édila Vilela de Resende Von Pinho(1), Renzo Garcia Von Pinho(1) \\ e César Martoreli da Silveira(1)
}

\begin{abstract}
(1)Universidade Federal de Lavras, Dep. de Agricultura, Caixa Postal 37, CEP 37200-000 Lavras, MG. E-mail: marsol@ufla.br, edila@ufla.br, renzo@ufla.br, cmspirangi@hotmail.com
\end{abstract}

\begin{abstract}
Resumo - Na aquisição e manutenção da tolerância à dessecação de sementes, há vários mecanismos envolvidos, entre eles a indução das proteínas resistentes ao calor. O objetivo deste trabalho foi avaliar mudanças no padrão eletroforético das proteínas resistentes ao calor de sementes de milho submetidas a alta temperatura de secagem, associando-as à sua tolerância. Foram utilizadas sementes de linhagens, híbridos simples e híbridos recíprocos colhidas com teor de água de aproximadamente $35 \%$ e secadas a $45^{\circ} \mathrm{C}$. Sementes das linhagens secadas à sombra foram utilizadas como controle e sua qualidade fisiológica foi avaliada por meio do teste de germinação. As proteínas resistentes ao calor foram extraídas de eixos embrionários das sementes em tampão Tris $\mathrm{HCl}$ 0,05 M. Não foi possível determinar uma banda específica da fração das proteínas resistentes ao calor que possa servir como marcador da tolerância à alta temperatura de secagem. Houve estabilidade nos padrões de bandas das proteínas provenientes de sementes submetidas à secagem artificial e natural, mesmo quando foram observadas variações nos valores de germinação. Os padrões eletroforéticos das proteínas resistentes ao calor foram semelhantes entre as sementes híbridas e os respectivos recíprocos.
\end{abstract}

Termos para indexação: Zea mays, dessecação, germinação, eletroforese, proteínas de choque térmico.

\section{Electrophorectic pattern of the heat resistant proteins of corn seeds}

\begin{abstract}
Several mechanisms are involved in the acquisition and maintenance of desiccation tolerance by the seeds. One of these mechanisms is related to the induction of heat resitant proteins. The objective of this work was to evaluate changes in the electophorectic patterns of the heat resistant proteins of corn seeds submitted to high drying temperature associating their expression with drying tolerance. Seeds of breeding lines, simple hybrids and respective reciprocals hybrids were utilized. The seeds were harvested with approximately $35 \%$ of water content and dried at $45^{\circ} \mathrm{C}$. Seeds of lines dried under shadow were used as control and the physiological quality was evaluated by germination test. The heat resistant proteins were extracted from embryonic axis of seeds in Tris- $\mathrm{HCl} 0.05 \mathrm{M}$ buffer. It was not possible to determine a specific band of heat resistant proteins which can be of use as a molecular marker of tolerance to high drying temperature. There was stability in the patterns of the bands of proteins of seeds submitted to artificial drying compared to the ones after shadow drying even for the lines of high variation in the germination values. The electrophorectic patterns of the heat resistant proteins were similar for both the hybrid seeds and respective reciprocals.
\end{abstract}

Index terms: Zea mays, desiccation, germination, electrophoresis, heat shock protein.

\section{Introdução}

Sementes tolerantes à dessecação e que sobrevivem em estado desidratado por períodos maiores, dependendo das condições de armazenamento, são designadas ortodoxas (Pammenter \& Berjak, 1999). Estas sementes, após a histodiferenciação e antes da secagem na maturação, adquirem habilidade para germinar e tolerar a dessecação (Bewley \& Black, 1994), sendo que sua maior tolerância é observada na secagem lenta, presumivelmente por causa do tempo concedido para a indução e operação dos mecanismos de proteção. Já a secagem rápida impede os processos de recuperação, sendo necessário maior tempo para os reparos na reidratação (Oliver \& Bewley, 1997, citados por Pammenter \& Berjak, 1999).

Devido ao fato de a água afetar as condições da célula, os tecidos que sobrevivem à sua remoção têm uma 
combinação de estratégias para limitar os danos resultantes da desidratação. Organismos que sobrevivem à remoção de água possuem constituintes celulares protegidos ou reparados (Walters et al., 2001).

Vários mecanismos têm sido associados à aquisição e manutenção da tolerância à dessecação de sementes, conferindo proteção contra as conseqüências da perda de água em diferentes níveis de hidratação. Porém, nenhum mecanismo é, por si só, responsável por esta tolerância; cada componente é igualmente crítico, atuando em sinergismo e controlado geneticamente (Leprince et al., 1993). A ausência ou inefetiva expressão de um ou mais destes mecanismos determina o grau relativo de sensibilidade à dessecação (Pammenter \& Berjak, 1999). Sementes que toleram a dessecação dispõem de alguns mecanismos de proteção capazes de manter os sistemas de membranas das células, as estruturas das macromoléculas e as substâncias de reserva em condições de readquirir suas funções fisiológicas quando as sementes são reembebidas (Guimarães, 1999; Walters et al., 2001).

Durante a maturação das sementes ocorrem mudanças na natureza das proteínas a serem sintetizadas. A dessecação de sementes em desenvolvimento é caracterizada pelo acúmulo de um grupo particular de mRNAs e proteínas LEA, late "embryogenesis accumulated" relacionadas. Os mRNA de proteínas LEA aparecem em tecidos embrionários, no começo da dessecação, e tornam-se as mais prevalecentes espécies de mRNA no estado seco, declinando progressivamente várias horas após embebição da semente (Baker et al., 1988; Galau et al., 1991).

Proteínas do tipo LEA são ricas em glicina e outros aminoácidos hidrofílicos e apresentam poucos resíduos hidrofóbicos, são extraídas em condições de alta temperatura e não apresentam nenhuma atividade catalítica aparente. Essas proteínas resistentes ao calor, por sua natureza conservada, propriedades físicas e abundância, têm sido associadas com a tolerância à dessecação das sementes (Blackman et al., 1991; Kigel \& Galili, 1995).

Foi sugerido que as proteínas LEA podem ligar íons e água, podendo ainda estar associadas aos açúcares, controlando a taxa de perda de água e mantendo, assim, a viabilidade das sementes ortodoxas no estado seco (Walters et al., 1997, citados por Pammenter \& Berjak, 1999). Por sua natureza anfipática, essas proteínas são capazes de inibir a denaturação de macromoléculas e estabilizar estruturas intracelulares sob condições de estresse, incluindo estresse hídrico severo (Blackman et al., 1995; Close, 1997).

Um dos mecanismos mais estudados na adaptação dos organismos à condição de estresse é a indução de proteínas resistentes ao calor, heat shock proteins (HSP), o qual inclui várias famílias de proteínas conservadas. Segundo Vertucci \& Farrant (1995), a função das HSP tem sido relacionada com a preservação e o reparo das estruturas macromoleculares durante a desidratação ou reidratação, respectivamente. Embora todos os organismos sintetizem HSP em resposta ao calor, o balanço de proteínas sintetizadas e a relativa importância das famílias individuais de HSP na tolerância ao estresse variam enormemente entre organismos (Queitsch et al., 2000).

As principais classes das HSP, citadas por Hong \& Vierling (2000), estão presentes em plantas e incluem proteínas de peso molecular que variam de 15 a $28 \mathrm{kDa}$; Hsp60; Hsp70; Hsp90 e Hsp100. A Hsp101, que é requerida para a termotolerância em bactéria e levedura, é também essencial para a termotolerância em eucariontes (Gurley, 2000).

Proteínas resistentes ao calor foram identificadas em eixos embrionários de sementes de soja. O nível destas proteínas foi correlacionado com a tolerância à dessecação, tanto na fase de desenvolvimento como na germinação das sementes, aumentando 44 dias após o florescimento, quando a tolerância à dessecação foi alcançada, e diminuindo após 18 horas de embebição, quando a tolerância foi perdida. Um conjunto de sete proteínas estáveis ao calor estava consistentemente presente quando as sementes estavam tolerantes à dessecação, com três proteínas com pesos moleculares de aproximadamente 70, 64 e 25,5 $\mathrm{kDa}$ e um grupo de quatro proteínas com peso molecular variando de $32 \mathrm{a}$ $40 \mathrm{kDa}$. Sementes de soja em desenvolvimento acumulam proteínas da maturação estáveis ao calor, porém, o desenvolvimento da tolerância à dessecação não se correlaciona com este acúmulo. Segundo os autores, a habilidade ou a falta de algum fator para expressar LEAs ou proteínas semelhantes às deidrinas, por si própria, não pode ser tomada como um indicativo de que as sementes de uma espécie em particular podem ou não resistir à desidratação (Blackman et al., 1991).

O objetivo deste trabalho foi avaliar mudanças nos padrões eletroforéticos das proteínas resistentes ao calor de sementes híbridas e de linhagens de milho que pudessem estar associados com a tolerância à alta temperatura de secagem. 


\section{Material e Métodos}

Foi instalado, em novembro de 1999, um campo de multiplicação das linhagens, provenientes da empresa Geneseeds - Recursos Genéticos em Milho Ltda. No florescimento, as espigas foram protegidas com sacos de plástico, antes da emissão dos estilo-estigmas, para evitar cruzamentos indesejáveis e, posteriormente, foram realizadas as autofecundações. Durante o desenvolvimento das sementes, foi feito um acompanhamento da solidificação do endosperma por meio da linha de leite e as espigas foram amostradas para determinação do teor de água, utilizando-se o método da estufa a $130^{\circ} \mathrm{C}$, por 4 horas, conforme prescrições das Regras para Análise de Sementes (Brasil, 1992), até que o teor de água das mesmas atingisse aproximadamente 35\%, quando foi realizada a colheita.

As espigas, correspondentes a cada linhagem, foram colhidas, despalhadas manualmente e em seguida foram submetidas à secagem artificial a $45^{\circ} \mathrm{C}$, até que as sementes atingissem o conteúdo de água de aproximadamente $11 \%$, em secadores experimentais de pequena escala, construídos de acordo com Navratil \& Burris (1982). O secador constava de uma câmara de secagem $(61 \times 61 \times 61 \mathrm{~cm})$ e gavetas empilháveis $(61 \times 61 \times 15,2 \mathrm{~cm})$, subdivididas em quatro seções, nas quais as espigas foram aleatoriamente distribuídas. O sistema de aquecimento foi realizado por meio de um conjunto de resistências (5.000 Watts), e a temperatura no leito de secagem foi verificada com o auxílio de um termo-cabo contendo um sensor. Do lado externo da base de cada secador foi montado um ventilador centrífugo, ligado a um motor de $0,25 \mathrm{~kW}, 115 \mathrm{~V}$, capaz de elevar $196 \mathrm{~L} \mathrm{~s}^{-1}$ a 7,6 cm de pressão estática. O fluxo médio de ar, de $23,0 \mathrm{~m}^{3} \mathrm{~min}^{-1} \mathrm{t}^{-1}$, foi ajustado por meio de uma portinhola deslizável, fixada na entrada do ventilador. Após a secagem, as espigas foram debulhadas manualmente e as sementes, retidas na peneira 16 de crivo circular, foram tratadas com os fungicidas Tecto 600 e Captan, nas doses de $40 \mathrm{~g}$ e $120 \mathrm{~g}$ do produto comercial por $100 \mathrm{~kg}$ de sementes, respectivamente. Sementes secadas à sombra foram utilizadas como controle.

A partir das linhagens foram obtidas as sementes dos híbridos simples e respectivos recíprocos. A semeadura, realizada em novembro de 2000, foi conduzida em três épocas distintas para garantir a coincidência no florescimento entre os parentais. Concomitantemente foram produzidas sementes das linhagens por meio de autofecundação. As metodologias de colheita e seca- gem artificial das sementes foram as mesmas citadas e as sementes foram secadas até atingirem um teor de água em torno de $8 \%$.

As análises foram realizadas no Laboratório de Análise e de Técnicas Moleculares do Setor de Sementes da UFLA. Foram utilizadas sementes das linhagens produzidas nas duas safras e sementes de híbridos simples e respectivos recíprocos.

Após o beneficiamento, as sementes permaneceram armazenadas em câmara fria, com temperatura em torno de $15^{\circ} \mathrm{C}$ e umidade relativa em torno de $50 \%$, até a colheita de todos os materiais. O teste de germinação das sementes produzidas na safra 2000/2001 e secadas à sombra foi realizado após 16 meses de armazenamento em câmara fria, sob as mesmas condições. As linhagens 8, 9 e o híbrido $9 / 1$ produziram quantidades insuficientes de sementes, o que impossibilitou a realização de algumas análises.

A avaliação da qualidade fisiológica das sementes foi realizada pelo teste de germinação, conduzido com quatro repetições de 50 sementes, que foram semeadas entre papel toalha tipo Germitest umedecido com água destilada na proporção de $2,5 \mathrm{~mL}$ por $1 \mathrm{~g}$ de papel. As sementes permaneceram no germinador regulado para $25^{\circ} \mathrm{C}$ e as avaliações foram realizadas segundo recomendações das Regras para Análise de Sementes (Brasil, 1992).

$\mathrm{Na}$ análise das proteínas resistentes ao calor, sementes correspondentes a cada material foram embebidas durante cinco horas, para a extração dos eixos embrionários, os quais foram colocados em microtubos e mantidos a $-86^{\circ} \mathrm{C}$ até a extração das proteínas. No momento da extração das proteínas, 11 eixos embrionários, previamente pesados, foram moídos em almofariz sobre gelo, na presença de solução tampão $(50 \mathrm{mM}$ Tris-HCL pH 7,5, $500 \mathrm{mM} \mathrm{NaCl}, 5 \mathrm{mM} \mathrm{MgCl} 2,1 \mathrm{mM}$ PMSF) na proporção de 1:10, peso do material:volume do tampão de extração, e transferidos para microtubos de capacidade de $1.500 \mathrm{~mL}$. O homogeneizado foi centrifugado a $16.000 \mathrm{~g}$ por 30 minutos, a $4^{\circ} \mathrm{C}$, o sobrenadante foi incubado em banho-maria a $85^{\circ} \mathrm{C}$ por 15 minutos e novamente centrifugado, como citado. $\mathrm{O}$ sobrenadante foi vertido em microtubos e o precipitado, descartado. Antes da aplicação no gel, os tubos contendo $70 \mu \mathrm{L}$ de extrato $+40 \mu \mathrm{L}$ de solução tampão da amostra $(2,5 \mathrm{~mL}$ de glicerol, 0,46 g de SDS, $20 \mathrm{mg}$ de azul de bromofenol e o volume completado para $20 \mathrm{~mL}$ de tampão de extração Tris $\mathrm{pH}$ 7,5) foram colocados em banho-maria com água em ebulição por 5 minutos. Foram aplicados $50 \mathrm{~mL}$ da amostra (extrato + tampão da amostra) por 
canaleta no gel de poliacrilamida SDS-PAGE a 12,5\% (gel separador) e 6\% (gel concentrador). A corrida eletroforética foi realizada a $150 \mathrm{~V}$ e os géis foram corados durante 12 horas em Coomassie Blue Brilliant a 0,05\%, conforme Alfenas et al. (1991), e descorados em solução de ácido acético $10 \%$.

\section{Resultados e Discussão}

Os padrões eletroforéticos das proteínas resistentes ao calor dos eixos embrionários das sementes das linhagens, produzidas na safra 1999/2000, e submetidas à secagem artificial a alta temperatura e secagem natural estão representados na Figura 1.

Houve estabilidade nos padrões de bandas das proteínas, consideradas robustas, nas sementes submetidas às secagens artificial e natural, mesmo naquelas em que houve grandes variações nos valores de germinação, a exemplo das linhagens 7 a 12, não tolerantes à secagem artificial (Figura 1, Tabela 1). Essa estabilidade sugere que o método de secagem não induziu mudanças no padrão protéico dessas sementes. Guimarães (2000) constatou a presença das proteínas resistentes ao calor em todos os estádios de desenvolvi-


Figura 1. Padrão eletroforético das proteínas resistentes ao calor do eixo embrionário de sementes de linhagens de milho tolerantes (a) e intolerantes (b) à alta temperatura de secagem, produzidas na safra 1999/2000. (s: após secagem artificial; c: controle, sementes secadas à sombra; P: padrão protéico da Bio-Rad, catálogo 161-0324, controle 86787).

Tabela 1. Germinação (\%) de sementes de linhagens de milho produzidos nas safras 1999/2000 e 2000/2001 e submetidas à secagem artificial e secagem à sombra, e de híbridos, produzidas em 2000/2001 e secadas artificialmente.

\begin{tabular}{|c|c|c|c|c|c|c|c|c|}
\hline \multirow[t]{3}{*}{ Identificação } & \multicolumn{4}{|c|}{ Linhagens } & \multicolumn{4}{|c|}{ Híbridos } \\
\hline & \multicolumn{2}{|c|}{ Safra $1999 / 2000$} & \multicolumn{2}{|c|}{ Safra $2000 / 2001$} & \multirow[t]{2}{*}{ Identificação } & \multirow[t]{2}{*}{ Germinação } & \multirow[t]{2}{*}{ Identificação } & \multirow[t]{2}{*}{ Germinação } \\
\hline & Sec. artificial & Sec. natural & Sec. artificial & Sec. natural & & & & \\
\hline 1 & 95 & 76 & 8 & 92 & $7 / 5$ & 90 & $4 / 8$ & 96 \\
\hline 2 & 100 & 96 & 12 & 83 & $5 / 7$ & 68 & $8 / 4$ & 59 \\
\hline 3 & 99 & 98 & 63 & 83 & $9 / 6$ & 40 & $4 / 10$ & 92 \\
\hline 4 & 99 & 99 & 49 & 91 & $6 / 9$ & 95 & $10 / 4$ & 45 \\
\hline 5 & 99 & 99 & 82 & 88 & $8 / 6$ & 13 & $1 / 7$ & 40 \\
\hline 6 & 99 & 100 & 30 & 96 & $6 / 8$ & 82 & $7 / 1$ & 92 \\
\hline 7 & 66 & 92 & 16 & 91 & $3 / 8$ & 1 & $2 / 7$ & 33 \\
\hline 8 & 59 & 98 & 4 & $-^{(1)}$ & $8 / 3$ & 90 & $7 / 2$ & 86 \\
\hline 9 & 55 & 97 & $-(1)$ & 99 & $11 / 1$ & 60 & $1 / 9$ & 97 \\
\hline 10 & 57 & 99 & 78 & 86 & $1 / 11$ & 0 & $9 / 1$ & $-(1)$ \\
\hline 11 & 56 & 100 & 60 & 90 & & & & \\
\hline 12 & 11 & 97 & 3 & 96 & & & & \\
\hline
\end{tabular}

(1) Tratamento não avaliado. 
mento de sementes de café, independentemente do método de secagem. No entanto, sementes que não foram submetidas ao processo de secagem, apresentaram a ausência de algumas bandas. Neste trabalho, as proteínas resistentes ao calor foram induzidas nas sementes de todas as linhagens que foram submetidas a secagem, seja artificial ou natural. Burris et al. (1997), analisando o padrão eletroforético das proteínas resistentes ao calor extraídas de eixos embrionários de milho, observaram que a fração protéica de peso molecular de $66 \mathrm{kDa}$ foi induzida e acumulada pelo processo de secagem. Porém este acúmulo foi menor no tratamento no qual as sementes foram secadas rapidamente.

Essa estabilidade no padrão eletroforético das proteínas resistentes ao calor também foi verificada entre as sementes das linhagens produzidas nas duas safras e secadas artificialmente (Figuras 1 e 2). Embora os valores de germinação, na maioria das sementes das linhagens produzidas na safra 2000/2001 após secagem artificial, tenham sido inferiores aos da safra 1999/2000 (Tabela 1), não houve mudança nos padrões das proteínas resistentes ao calor.

Não foi possível determinar uma banda específica da fração das proteínas resistentes ao calor que possa servir como marcador de tolerância à alta temperatura de secagem. Essas proteínas estavam presentes nas sementes de todas as linhagens, porém o de-

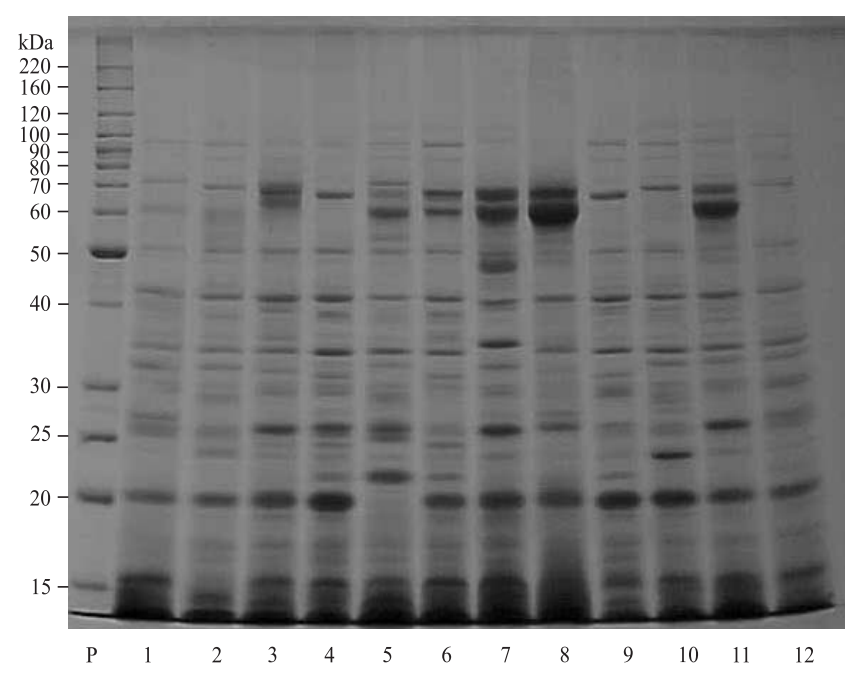

Figura 2. Padrão eletroforético das proteínas resistentes ao calor do eixo embrionário de sementes de linhagens de milho produzidas na safra 2000/2001 e submetidas à secagem artificial à alta temperatura (P: padrão protéico da Invitrogen, catálogo 10747-012). senvolvimento da tolerância à alta temperatura de secagem não se correlacionou com esse acúmulo. Blackman et al. (1991) verificaram que as proteínas resistentes ao calor foram induzidas e acumuladas durante a maturação in vitro de embriões de soja, sob condições de alta umidade relativa, o que preservou a intolerância à dessecação. Isto sugere que a habilidade ou falta de algum fator para expressar as proteínas LEA ou proteínas semelhantes às deidrinas, por si só, não pode ser tomada como um indicativo de que as sementes de uma espécie em particular podem ou não resistir a desidratação. Como mencionado por Queitsch et al. (2000), embora todos os organismos sintetizem HSP em resposta ao calor, o balanço de proteínas sintetizadas e a relativa importância das famílias individuais de HSP na tolerância a estresse variam enormemente entre organismos.

Diferenças na expressão fenotípica entre híbridos e recíprocos têm sido observadas para várias características. Kollipara et al. (2002) observaram uma expressão diferenciada de genes envolvidos na degradação protéica, tais como proteases e proteínas associadas à mobilização de proteínas para os proteossomas, bem como no perfil protéico da globulina para os recíprocos divergentes para tolerância a dessecação em embriões de sementes de milho. Nesta pesquisa, embora tenham sido constatadas diferenças quanto à qualidade fisiológica entre as sementes híbridas e de seus respectivos recíprocos (Tabela 1), o mesmo não ocorreu nos padrões protéicos de proteínas resistentes ao calor (Figura 3). O fato de o padrão eletroforético das frações protéicas das proteínas resistentes ao calor não terem se alterado entre os híbridos e recíprocos confirma que a expressão dessas proteínas é controlada por genes presentes no núcleo, pois caso ocorresse diferenças nos resultados de um cruzamento e de seu recíproco, o caráter em questão seria devido ao efeito materno e/ou citoplasmático, ou seja, os descendentes de cada cruzamento teriam o mesmo fenótipo do genitor feminino (Ramalho et al., 1990).

Vários mecanismos têm sido associados com a manutenção da tolerância a dessecação, conferindo proteção contra as conseqüências da perda de água. Embora as sementes tenham acumulado essas proteínas durante o seu desenvolvimento, sua presença por si só parece não ser responsável pela tolerância à alta temperatura de secagem, e outros fatores devem estar influenciando essa característica. 


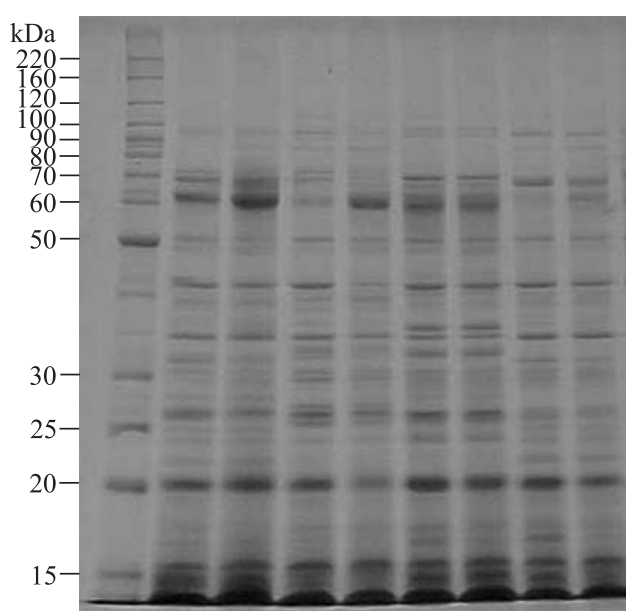

$\begin{array}{lllllllll}\text { P } & 6 / 8 & 8 / 6 & 11 / 1 & 1 / 11 & 7 / 2 & 2 / 7 & 6 / 9 & 9 / 6\end{array}$

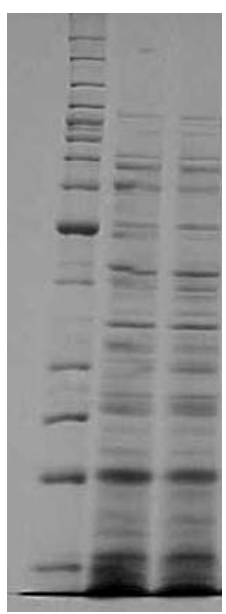

$\begin{array}{lll}\text { P } & 1 / 9 & 9 / 1\end{array}$

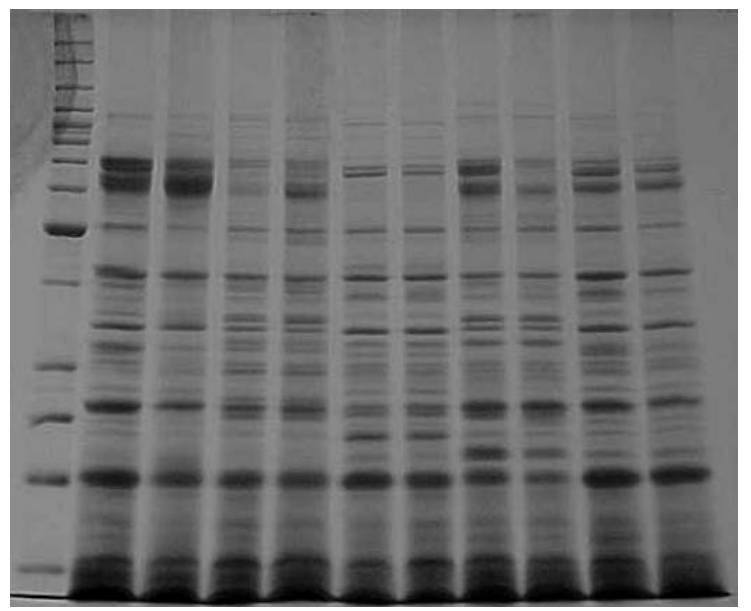

$\begin{array}{lllllllllll}\text { P } & 8 / 3 & 3 / 8 & 7 / 1 & 1 / 7 & 4 / 10 & 10 / 4 & 7 / 5 & 5 / 7 & 4 / 8 & 8 / 4\end{array}$

Figura 3. Padrão eletroforético das proteínas resistentes ao calor do eixo embrionário de sementes híbridas de milho e seus recíprocos, produzidas na safra 2000/2001 e submetidas à secagem artificial à alta temperatura (P: padrão protéico da Invitrogen, catálogo 10747-012).

\section{Conclusões}

1. Os padrões de proteínas resistentes ao calor são estáveis em sementes de linhagens de milho independentemente do método de secagem empregado.

2. Os padrões eletroforéticos das proteínas resistentes ao calor são semelhantes entre sementes híbridas e respectivos recíprocos.

\section{Referências}

ALFENAS, A.C.; PETERS, I.; BRUNE, W.; PASSADOR, G.C. Eletroforese de proteínas e isoenzimas de fungos e essências florestais. Viçosa: UFV, 1991. 242p.

BAKER, J.; STEELE, C.; DURE, L. III. Sequence and characterization of 6 Lea proteins and their genes from cotton. Plant Molecular Biology, v.11, p.277-291, 1988.

BEWLEY, J.D.; BLACK, M. Seeds: physiology of development and germination. 2.ed. New York: Plenum Press, 1994. 445p.

BLACKMAN, S.A.; OBENDORF, R.L.; LEOPOLD, A.C. Desiccation tolerance in developing soybean seeds: the role of stress proteins. Physiologia Plantarum, v.93, p.630-638, 1995.

BLACKMAN, S.A.; WETTLAUFER, S.H.; OBENDORF, R.L.; LEOPOLD, A.C. Maturation proteins associated with desiccation tolerance in soybean. Plant Physiology, v.96, p.868-874, 1991.

BRASIL. Ministério da Agricultura e Reforma Agrária. Regras para análise de sementes. Brasília, 1992. 365p.

BURRIS, J.S.; PETERSON, J.M.; PERDOMO, A.; FENG, D.S. Morphological and physiological changes associated with desiccation in maize embryos. In: INTERNATIONAL WORKSHOP ON SEEDS: basic and applied aspects of seed biology, 5., 1995, Reading. Proceedings. Reading: University of Reading, 1997. p.103-111.
CLOSE, T.J. Dehydrins: a commonality in the response of plants to dehydration and low temperature. Physiologia Plantarum, v.100, p.291-296, 1997.

GALAU, G.A.; JAKOBSEN, K.S.; HUGHES, D.W. The controls of late dicot embryogenesis and early germination. Physiologia Plantarum, v.81, p.280-288, 1991.

GUIMARÃES, R.M. Fisiologia de sementes. Lavras: UFLAFAEPE, 1999. 132p. (Curso de Especialização Pós-Graduação "Lato Sensu" por tutoria à distância).

GUIMARÃES, R.M. Tolerância à dessecação e condicionamento fisiológico em sementes de cafeeiro (Coffea arabica, L.). 2000. 180p. Tese (Doutorado) - Universidade Federal de Lavras, Lavras.

GURLEY, W.B. HSP: a key component for the acquisition of thermotolerance in plants. Plant Cell, v.12, p.457-460, 2000.

HONG, S.W.; VIERLING, E. Mutants of Arabidopsis thaliana defective in the acquisition of tolerance to high temperature stress. Proceedings of the National Academy of Science of the United States of America, v.97, p.4392-4397, 2000.

KIGEL, J.; GALILI, G. Seed development and germination. New York: Marcel Dekker, 1995. 853p.

KOLLIPARA, K.P.; SAAB, I.N.; WYCH, R.D.; LAUER, M.J.; SINGLETARY, G.W. Expression profiling of reciprocal maize hybrids divergent for cold germination and desiccation tolerance. Plant Physiology, v.129, p.974-992, 2002.

LEPRINCE, O.; HENDRY G.A.F.; McKERSIE, B.D. The mechanisms of desiccation tolerance in developing seeds. Seed Science Research, v.3, p.231-246, 1993.

NAVRATIL, R.J.; BURRIS, J.S. Small-scale dryer designer. Agronomy Journal, v.74, p.159-161, 1982.

PAMMENTER, N.W.; BERJAK, P. A review of recalcitrant seed physiology in relation to desiccation-tolerance mechanisms. Seed Science Research, v.9, p.13-37, 1999. 
QUEITSCH, C.; HONG, S.W.; VIERLING, E.; LINDQUIST, S. Heat shock protein 101 plays a crucial role in thermotolerance in Arabidopsis. Plant Cell, v.12, p.479-492, 2000.

RAMALHO, M.A.P.; SANTOS, J.B.; PINTO, C.B. Genética na Agropecuária. São Paulo: Globo; Lavras: FAEPE, 1990. $359 \mathrm{p}$.
VERTUCCI, C.W.; FARRANT, J. M. Acquisition and loss of desiccation tolerance. In: KIGEL, J.; GALILI, G. (Ed.). Seed development and germination. New York: Marcel Dekker, 1995. p.237-271.

WALTERS, C.; PAMMENTER, N.W.; BERJAK, P.; CRANE, J. Desiccation damage, accelerated ageing and respiration in desiccation tolerant and sensitive seeds. Seed Science Research, v.11, p.135-148, 2001.

Recebido em 19 de fevereiro de 2004 e aprovado em 28 de setembro de 2004 